\title{
Ovarian Cancer Revealed by Perineal Tumor: A Case Report and a Literature Review
}

\author{
Ahlam Bassir*, Hanane Dhibou, Lahcen Boukhanni, Bouchra Fakhir, Karam Harou, \\ Yasser Ait Benkeddour, Hamid Asmouki, Abderraouf Soummani \\ Cadi Ayyad University, Hospital University Center Mohammed VI, Marrakech, Morocco \\ Email: `bassirahlam@gmail.com, anane.dhibou@gmail.com, boukhani.lahcen@gmail.com, bouchrafakhir@gmail.com, \\ harou.karam@gmail.com, yaitbenkaddour@gmail.com, hasmouki@gmail.com, asoummani@gmail.com
}

How to cite this paper: Bassir, A., Dhibou, H., Boukhanni, L., Fakhir, B., Harou, K., Benkeddour, Y.A., Asmouki, H. and Soummani, A. (2016) Ovarian Cancer Revealed by Perineal Tumor: A Case Report and a Literature Review. Open Access Library Journal, 3: e2637.

http://dx.doi.org/10.4236/oalib.1102637

Received: October 3, 2016

Accepted: October 28, 2016

Published: October 31, 2016

Copyright ( 2016 by authors and Open Access Library Inc.

This work is licensed under the Creative Commons Attribution International License (CC BY 4.0).

http://creativecommons.org/licenses/by/4.0/

\begin{abstract}
Background: Cutaneous metastasis of ovarian epithelial adenocarcinoma is rare, and most cases present as cutaneous nodules, generally as periumbilical Sister Joseph's nodules. An uncommon presentation of cutaneous metastases from ovarian carcinoma is perineal tumor. Case: A 56-year-old patient has a serous adenocarcinoma reveled with a perineal tumor. After surgery, the patient started chemotherapy with bad evolution, and the patient died after 3 months. Conclusions: The prognosis of the cutaneous metastasis of the ovarian adenocarcinoma is poor, but palliative treatment is usually indicated that further studies evaluating the role of specific therapies are needed to guide treatment.
\end{abstract}

\section{Subject Areas \\ Gynecology \& Obstetrics}

\section{Keywords}

Ovarian Carcinoma, Metastasis, Perineal Tumor

\section{Introduction}

Ovarian cancer remains the leading cause of death among gynecologic cancers [1]. Patterns of metastasis in ovarian carcinoma are well described [2]. A clinical presentation of ovarian cancer varies, but common modes of presentation are abdominal pain, distention, or ascites due to metastatic involvement of peritoneal cavity. Most tumors present at advanced stage, therefore, primary and metastatic disease is diagnosed simultaneously. The cutaneous metastasis from primary ovarian cancer is very rare but is found in advanced disease [2]. The skin metastases occur in $3.5 \%$ of patients with ova- 
rian carcinoma [3].

The perineal metastasis is never reported in literature. We report a new case dan revealing symptom was that the perineal tumor.

\section{Case Report}

A 56 years old female, no medical history, menopausal for 15 years, consulted for perineal tumor, lasting for three months. Clinical examination revealed perineal tumor 8 $\mathrm{cm} / 9 \mathrm{~cm}$ with necrotic purulent places, fixed, the vulva is normal (Figure 1 ). The rest of the clinical examination is normal, a peripheral lymph nodes are free, absence of palpable abdominal mass and a pelvic examination normal.

Biopsy of the lesion showed a secondary location of adenocarcinoma of unknown primary origin, immunohistochemistry (CK positive, KIG7 negative, estrogen receptor and progesterone negative).

Abdomino pelvic scanner objectifying ovarian cyst left $5 \mathrm{~cm}$. CA 125 was normal.

A laparoscopy was indicated and left adnexectomy was realized, extemporaneous histological examination confirmed the diagnosis and the treatment were supplemented by a total hysterectomy and right adnexectomy. Histological examination of the surgical specimen confirmed the presence serous adenocarcinoma of the left ovary. Cytology ascites fluid revealed the presence of neoplastic cells question.

Balance sheet extension showed the presence of lung metastases (lesi anon of left lobe $3 \mathrm{~mm}$ ). The neoplasm was classified as stage IV. The treatment was chemotherapy associated paclitaxel and carboplatin, but the patient decided after the third chemotherapy session.

\section{Discussion}

In 2012, an estimated 22,280 women were diagnosed with ovarian cancer and 15,500 died of the disease [4]. Approximately seventy-five percent of women diagnosed with ovarian cancer in the United States have stage III or more advanced disease at diagnosis [5].

Skin involvement from ovarian carcinoma is uncommon. The incidence of ovarian

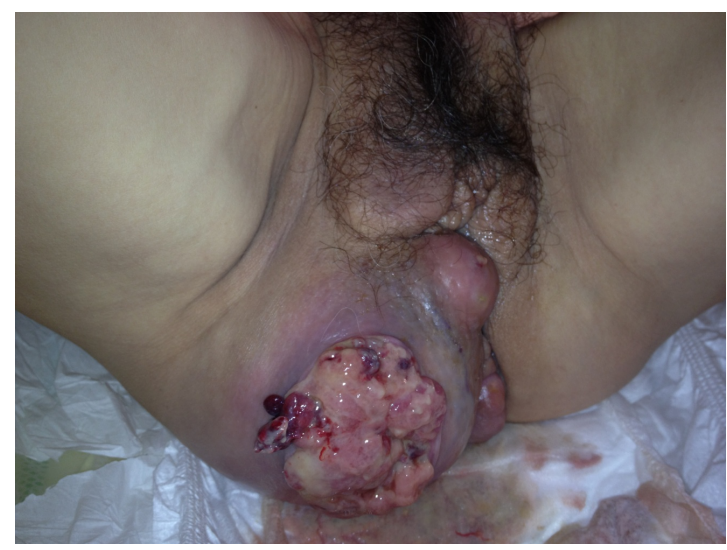

Figure 1. Perineal tumor $8 \mathrm{~cm} / 9 \mathrm{~cm}$ with necrotic purulent places. 
cancer metastasizing to the skin is variable ranging from $1.9 \%$ to $5.1 \%$ in different series, in a study of 220 patients with epithelial ovarian carcinoma treated at our unit between 1991 and 2001, the cutaneous metastases were found for 4\% [6]. In an autopsy study on 381 epithelial ovarian cancer, 20 patients (5\%) were found to have skin metastasis. On the other hand, in a clinical study on 255 patients, we found nine patients with skin metastases (3.5\%), Bronstein et al. found that ovarian carcinoma was the most rare origin for skin metastases, presenting only in $4 \%$ of all different primary tumors [7] [8] [9].

Although most patients respond to initial treatment, the rate of recurrence after initial treatment of ovarian cancer is as high as $65 \%$ to $75 \%$. The most commonsite of recurrence is within the peritoneal cavity. In a postmortem study, Rose et al. evaluated the patterns of ovarian cancer metastasis and found that the most common sites of metastasis were the peritoneal cavity, paraaortic lymph nodes, large intestine, pelvic lymph nodes, and liver [5]. Ovarian cancer can metastasize by direct extension and transport throughout the peritoneal cavity and, or through lymphatic or hematogenous spread.

The classic presentation with a "Sister Mary Joseph node" at the umbilicus from intra-abdominal extension vialymphatics is a well known example of skin metastases [10]. In Dauplat's study, seven of nine patients had abdominal cutaneous nodules, five of them being peri umbilical Sister Joseph's nodules. In their report, two of the nine patients presented with multiple nodules. Other sites for skin metastatic nodules were the chest wall, breast, and right buttock. Merimsky et al. presented three cases of skin metastases [11]. Two of the cases had multiple abdominal, wall nodules, and one of these had a Sister Joseph's nodule. In another report of a rare case, Traiman et al. presented a patient with advanced ovarian carcinoma who refused treatment and returned after 6 years with a large, $20-\mathrm{cm}$, cauliflower-type infected skin metastases [12]. An uncommon presentation of cutaneous metastases from ovarian epithelial carcinoma is the inflammatory pattern, which mimics herpetiform lesions to the skin [13]. In our study, the cutaneous metastasis was the origin of the revelation of serous adenocarcinoma ovarian. The location of the tumor in the perineal region is unique and it has never previously described.

Because skin metastases commonly present in the setting of advanced-stage, metastatic disease, the prognosis is poor [6] [10]. In the series of nine patients by Cormio, the median survival after presentation of skin metastasis was 4 months (range 2 - 65 months). The small numbers make comparison difficult between skin metastasis and other presentations of advanced ovarian cancer, but comparing to malignant small bowel obstruction, for example, with a median overall survival of 7 months [14], our patient is decided after 3 months of treatment, so skin metastasis could be seen as a marker of poor prognosis.

There are no published protocols for the treatment of isolated ovarian skin metastasis. In a case report from Turkey [15], a 43-year-old patient with isolated abdominal wall metastases was treated with $37.5 \mathrm{~Gy}$ in $2.5 \mathrm{~Gy} /$ day fractions of external beam radiation therapy. In follow-up she was noted to have tumor regression and was still alive at 
7 months of follow-up.

Earlier studies suggested that electrocoagulation, electron beam therapy, and phototherapy may be effective in treating cutaneous lesions. At present, the topical Toll-like receptor 7 agonist imiquimod and electrochemotherapy are being studied for treatment of cutaneous metastases [16] [17]. The electro chemotherapy, historically used in the treatment of metastatic head and neck cancers, has been explored in the treatment of cutaneous disease in patients with chest wall recurrence of breast cancer. Inelectrochemotherapy, a local electrical current is applied to the lesion, which causes cellular membranes to become more permeable to the chemotherapy agent being used. In the case of bleomycin-based electrochemotherapy, the electric current increases permeability to the drug by 700 -fold [18].

\section{Conclusion}

Management of cutaneous metastases varies widely and remains a clinical challenge, the prognosis is poor, and the treatment strategies depend on the associated disease burden, but for treatment of the skin lesion itself, roles have been suggested for multi-modal therapy including surgical resection of skin lesion, systemic chemotherapy, and external beam radiation therapy to the site of metastasis.

\section{Conflicts of Interest}

No.

\section{References}

[1] Howlader, N., Noone, A.M., Krapcho, M., Neyman, N., Aminou, R., Waldron, W., Altekruse, S.F., Kosary, C.L., Ruhl, J., Tatalovich, Z., Cho, H., Mariotto, A., Eisner, M.P., Lewis, D.R., Chen, H.S., Feuer, E.J., Cronin, K.A. and Edwards, B.K., Eds. (2011) SEER Cancer Statistics Review, 1975-2008. National Cancer Institute, Bethesda, MD. Based on November 2010 SEER Data Submission, Posted to the SEER Web Site. http://seer.cancer.gov/csr/1975_2008/

[2] Dauplat, J., Hacker, N.F., Nieberg, R.K., Berek, J.S., Rose, T.P. and Sagae, S. (1987) Distant Metastases in Epithelial Ovarian Carcinoma. Cancer, 60, 1561-1566.

http://dx.doi.org/10.1002/1097-0142(19871001)60:7<1561::AID-CNCR2820600725>3.0.CO; $\underline{2-\mathrm{V}}$

[3] Hardy, J.R. and Harvey, V.J. (1989) Cerebral Metastases in Patients with Ovarian Cancer Treated with Chemotherapy. Gynecologic Oncology, 33, 296-300. http://dx.doi.org/10.1016/0090-8258(89)90515-5

[4] Siegel, R., Naishadham, D. and Jemal, A. (2012) Cancer Statistics, 2012. CA: A Cancer Journal for Clinicians, 62, 10-29. http://dx.doi.org/10.3322/caac.20138

[5] Rose, P.G., Piver, M.S., Tsukada, Y. and Lau, T.S. (1989) Metastatic Patterns in Histologicvariants of Ovarian Cancer. An Autopsy Study. Cancer, 64, 1508-1513. http://dx.doi.org/10.1002/1097-0142(19891001)64:7<1508::AID-CNCR2820640725>3.0.CO; $\underline{2-\mathrm{V}}$

[6] Cormio, G., Capotorto, M., Di Vagno, G., Cazzolla, A., Carriero, C. and Selvaggi, L. (2003) Skin Metastases in Ovarian Carcinoma: A Report of Nine Cases and a Review of the Literature. Gynecologic Oncology, 90, 682-685. http://dx.doi.org/10.1016/S0090-8258(03)00400-1 
[7] White, J.W., Spencer, P.S. and Helm, T.N. (1987) Skin Metastases in Cancer Patients. Cutis, 39, 119-121.

[8] Krumerman, M. and Garret, R. (1977) Carcinoma Metastatic to Skin. New York State Journal of Medicine, 77, 1900-1903.

[9] Bronstein, H.M. and Helwig, E.B. (1972) Patterns of Cutaneous Metastases. Archives of Dermatology, 102, 862-868. http://dx.doi.org/10.1001/archderm.1972.01620090034008

[10] Tourad, J.P., Lentz, N., Dutronc, Y., Mercier, E., Sagot, P. and Lambert, D. (2000) Umbilical Cutaneous Metastasis (or Sister Mary Joseph's Nodule) Disclosing an Ovarian Adenocarcinoma. Gynécologie Obstétrique \& Fertilité, 28, 719-721.

[11] Merimsky, O., Chaitchik, S. and Inbar, M. (1991) Skin Metastases of Ovarian Cancer: Report of Three Cases. Tumori, 77, 268-270.

[12] Traiman, P., De Luca, L.A. and Bacchi, C.B. (1994) An Extremely Large, Cauliflower Type, Cutaneous Metastases of Ovarian Cancer Associated with Good Prognosis. Gynecologic Oncology, 53, 239-241. http://dx.doi.org/10.1006/gyno.1994.1122

[13] Schonmann, R., Altaras, M., Biron, T., Bernheim, J. and Fishman, A. (2003) Inflammatory Skin Metastases from Ovarian Carcinoma-A Case Report and Review of the Literature. Gynecologic Oncology, 90, 670-672. http://dx.doi.org/10.1016/S0090-8258(03)00366-4

[14] Sartori, E., Chiudinelli, F., Pasinetti, B., Sostegni, B. and Maggino, T. (2010) Possible Role of Palliative Surgery for Bowel Obstruction in Advanced Ovarian Cancer Patients. European Journal of Gynaecological Oncology, 21, 31-36.

[15] Demirci, S., Yavas, F., Ozsaran, Z., Ozsaran, A., Dikmen, Y., Zekioglu, O., Karabulut, B. and Aras, A.B. (2010) Palliative Radiotherapy for the Skin Metastasis of Ovarian Cancer: A Case Report and Review of the Literature. Medical Oncology, 27, 628-631. http://dx.doi.org/10.1007/s12032-009-9259-z

[16] Stanley, M.A. (2002) Imiquimod and the Imidazoquinolones: Mechanism of Action and Therapeutic Potential. Clinical and Experimental Dermatology, 27, 571-577. http://dx.doi.org/10.1046/j.1365-2230.2002.01151.x

[17] Craig, C.D., Iglesias, D.A., Watkins, J., Coleman, R.L., Kilgore, L. and Ramirez, P.T. (2013) Extensive Cutaneous Metastases of Ovarian Cancer after Prolonged Response to Liposomal Doxorubicin. Gynecologic Oncology Reports, 5, 64-66. http://dx.doi.org/10.1016/j.gynor.2013.05.005

[18] Campana, L.G., Valpione, S., Falci, C., et al. (2012) The Activity and Safety of Electrochemotherapy in Persistent Chest Wall Recurrence from Breast Cancer after Mastectomy: A Phase-II Study. Breast Cancer Research and Treatment, 134, 1169-1178. http://dx.doi.org/10.1007/s10549-012-2095-4 
Submit or recommend next manuscript to OALib Journal and we will provide best service for you:

- Publication frequency: Monthly

- 9 subject areas of science, technology and medicine

- Fair and rigorous peer-review system

- Fast publication process

- Article promotion in various social networking sites (LinkedIn, Facebook, Twitter, etc.)

- Maximum dissemination of your research work

Submit Your Paper Online: Click Here to Submit

Or Contact service@oalib.com 